\title{
A Lei de Responsabilidade Fiscal (LRF) e o impacto sobre o endividamento dos municípios potiguares
}

\author{
Gilmar Ribeiro de Mello \\ Doutor e Mestre em Ciências Contábeis \\ pela Universidade de São Paulo (FEA/USP) \\ Professor Adjunto da Universidade Estadual \\ do Oeste do Paraná (CCSA/UNIOESTE) \\ gilmarribeirodemello@gmail.com
}

\section{Eloisa Carla Dalchiavon}

Acadêmica do Curso de Ciências Econômicas, da Universidade Estadual do Oeste do Paraná

Bolsista de iniciação científica PIBIC/UNIOESTE

e-mail:elo.01@hotmail.com

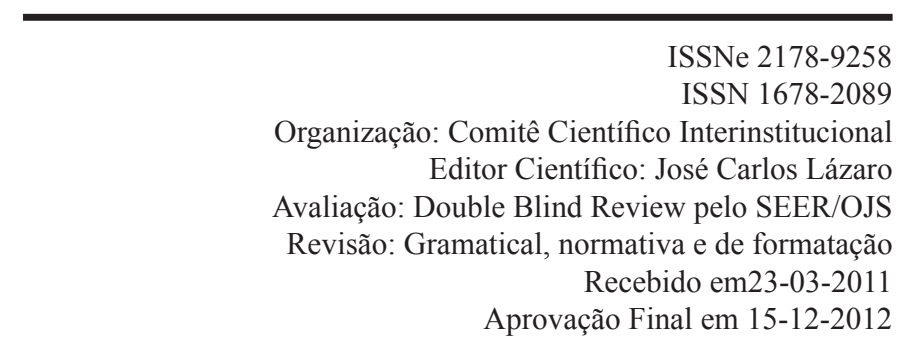

\section{RESUMO:}

O endividamento dos Estados e Municípios brasileiros, oriundo da década de 70 e até hoje sem uma solução satisfatória, é uma questão central do processo de ajuste do setor público. O esforço de redução da dívida culminou com a implantação da Lei de Responsabilidade Fiscal (LRF), que tem como um dos objetivos o controle do endividamento. Nesse contexto, o propósito deste artigo é verificar a situação das finanças dos Municípios Potiguares após a implantação da LRF no que diz respeito à redução de endividamento e ao cumprimento dos seus limites. Para verificar se houve essa redução foram selecionados quatro indicadores, calculados para o período de 1998 a 2003. Em seguida, foi aplicado o teste de hipótese de diferenças de médias para observações emparelhadas, não-paramétrico, denominado de Wilcoxon. Com o intuito de examinar se os Municípios Potiguares cumpriram com os limites estabelecidos, foi analisado o período de 2001 a 2009, em que os resultados dos indicadores de endividamento foram comparados com os seus respectivos limites. As evidências indicam que a LRF pode ter cumprido com seu objetivo de controlar o avanço do endividamento mediante a fixação de regras e limites. Mas, ao comparar os resultados encontrados dos Municípios Potiguares e os Paranaenses, observou-se que os Potiguares são mais endividados.

Palavras-chave: Endividamento. Lei de Responsabilidade Fiscal. Municípios Potiguares. Dívida Pública. Wilcoxon.

\section{ABSTRACT:}

The indebtedness of the Brazilian States and Municipalities comes from the 70's and still without a satisfactory solution, is a central issue of the adjustment process in the public sector. The effort to reduce debt culminated with the implementation of the LRF, which aims, among others, is to control the debt. In this context, the aim of this paper is to verify the situation of the indebtedness of Potiguares Municipalities after the implementation of the LRF, concerning to its reduction and regards limits. To check whether there was a reduction in indebtedness selected four indicators, calculated for the period 1998 to 2003. Then we applied the hypothesis test of differences in means for paired observations, nonparametric, Wilcoxon called. To check whether the Potiguares Municipalities complied with the limits, we analyzed the period from 2001 to 2009, where the results of the indebtedness indicators were compared with their respective limits. The evidences confirm that the LRF may have accomplished its purpose of controlling the spread of indebtedness by setting rules and limits. But, when comparing the results of Potiguares Municipalities and the Paranaenses, it was observed that the Potiguares are most indebted.

Keywords: Indebtedness. Fiscal Responsibility Law. Potiguares Municipalities. Public Debt. Wilcoxon. 


\section{INTRODUÇÃO}

Após mais de 10 anos de vigência da Lei de Responsabilidade Fiscal (LRF), criada com o objetivo principal de melhorar a administração das contas públicas no Brasil, ainda se tem notícias de seu descumprimento. Para Costa (2007), diferentemente das tentativas anteriores para a limitação dos gastos públicos, a LRF trouxe inovação no planejamento governamental e punição aos que não se enquadram nos limites estabelecidos, os quais poderão ficar impedidos, enquanto perdurar a irregularidade, de contratar operações de crédito nos contratos de refinanciamento de suas respectivas dívidas com a União.

ALRF, no $\S 1^{\circ}$, do art. $1^{\circ}$, estabelece que a responsabilidade na gestão fiscal pressupõe a ação planejada e transparente, em que se previnem riscos e corrigem desvios capazes de afetar o equilíbrio das contas públicas, mediante o cumprimento de metas de resultados entre receitas e despesas e a obediência a limites e condições no que tange, por exemplo, às dívidas (BRASIL, 2001a).

Segundo Decat (2009), o cumprimento da LRF provoca grandes discordâncias entre os especialistas, principalmente quanto aos limites de gastos que os Estados, os Municípios e a União devem cumprir.

Para Riani (1990), ao analisar a trajetória das contas correntes na administração pública, percebe-se que a partir da década de 80 o governo passa de uma situação superavitária para constantes déficits. A solução encontrada foi a aquisição de empréstimos, e a dívida passou a ser um problema permanente, entrando o governo num processo de "rolagem da dívida".

De acordo com o Banco Central (2010), a dívida líquida do setor público atingiu $\mathrm{R} \$ 1.417,3$ bilhões $(41,4 \%$ do Produto Interno Bruto - PIB) em agosto de 2010, mantendo-se estável, como percentual do PIB, em relação ao mês anterior. A Dívida Bruta do Governo Geral (governo federal, INSS, governos estaduais e governos municipais) atingiu $\mathrm{R} \$ 2.034,9$ bilhões $(59,4 \%$ do $\mathrm{PIB})$, comparativamente a $\mathrm{R} \$ 2.027,6$ bilhões $(59,6 \%$ do PIB) em julho de 2010.
Diante disso, este trabalho tem a seguinte questão de pesquisa: quais evidências podem ser consideradas para verificar se a LRF cumpriu com o objetivo de diminuir o endividamento dos Municípios Potiguares?

Para responder essa questão, estabeleceu-se o objetivo de verificar a situação deficitária dos Municípios Potiguares após a implantação da LRF, no que diz respeito à redução de endividamento e ao cumprimento dos seus limites.

Dessa forma, as hipóteses construídas para esta pesquisa são: o endividamento dos Municípios Potiguares antes da LRF é igual ao endividamento após a LRF ou, de forma alternativa, é diferente.

\section{REFERENCIAL TEÓRICO}

\subsection{Dívida Pública}

Segundo Pego Filho e Pinheiro (2004), a dívida pública é o estoque de obrigações que o setor público acumula com o setor privado. Tais obrigações podem assumir diversas formas: títulos, base monetária, dívida bancária ou quaisquer outros contratos de que resultem direitos dos agentes privados contra o governo. Este, por sua vez, também possui créditos junto às pessoas físicas e jurídicas e junto ao setor financeiro.

De acordo com Torres (1993, p. 175),

O conceito de dívida pública, no direito financeiro, é restrito e previamente delimitado. Abrange apenas os empréstimos captados no mercado financeiro interno e externo, através de contratos assinados com os bancos e instituições financeiras ou do oferecimento de títulos ao público em geral. Estende-se, ainda, à concessão de garantias e avais, que potencialmente podem gerar endividamento. Excluem-se, portanto, do conceito de dívida pública aquelas que se caracterizam como dívida da Administração, como sejam as relativas a aluguéis, aquisição de bens, prestação de serviços, condenações judiciais etc. Também está fora do conceito de empréstimo a emissão de papel moeda, que só no sentido econômico dele pode se aproximar. 
Essa dívida pode ser entendida ainda, de forma mais generalizada, como sendo uma denominação dada ao conjunto de obrigações ou compromissos ou assumidos pelo governo para fazer face aos déficits orçamentários ou para atender a despesas de caráter extraordinário e urgente (CGRN, 1999).

A dívida pública é dividida em dívida consolidada e dívida flutuante, a primeira compreendendo as obrigações realmente assumidas pelo Estado, a título de empréstimo, e a segunda significando o conjunto de débitos contraídos pelo Estado para atender às necessidades momentâneas ou para solver encargos, oriundos da administração de bens de terceiros, confiados à sua guarda.

Portanto, a dívida líquida do setor público é dada pela soma das dívidas interna e externa do setor público (governo central, Estados, Municípios e empresas estatais) junto ao setor privado, somada a base monetária e excluídos os ativos do setor público, tais como reservas internacionais, créditos com o setor privado e valores das privatizações, aumentos da dívida pública e do déficit impactam sobre o nível de poupança doméstica, investimentos e formação de capital, podendo interferir inclusive na taxa de juros, nas transações externas e na taxa de câmbio (REZENDE, 2001).

Para Pedras (2009), a dívida pública é economicamente justificável por quatro objetivos básicos, quais sejam: (i) financiar o déficit público; (ii) proporcionar maneiras adequadas para a realização da política econômica; (iii) servir como base de longo prazo para financiamento do setor privado, já que as emissões públicas, dados seu alto volume e menor risco de crédito, servem como referência para a precificação da dívida pública; (iv) propiciar a alocação de recursos entre gerações, na medida em que à geração futura caberá o pagamento das despesas realizadas no presente com recursos oriundos do endividamento.

O endividamento público municipal teve início na década de 70 com a descentralização administrativa e a captação de recursos externos (MENDES, 2002). Porém, já em 1964, o governo Castelo Branco lança o Plano de Ação Econômica do Governo (PAEG), introduzindo reformas do sistema fiscal e financeiro e correção monetária sobre os títulos públicos, prevendo também um programa "desinflacionário" e uma série de reformulações emergenciais da legislação econômica, sobretudo, a lei salarial.

Como reafirma Rosar (2007), a origem da deterioração das finanças públicas pode ser entendida pelo contexto da política de ajuste monetário da balança de pagamento praticada a partir de 1976, com o aumento da taxa de juros com a finalidade de reduzir a absorção doméstica, e com a ampliação da taxa de juros para aumentar a captação de recursos externos. $\mathrm{O}$ acúmulo de reservas em virtude dessa política criou um excesso de liquidez indesejado, que era controlado através da emissão de dívida pública (dívida mobiliária federal).

Nesse período, segundo Costa (2007), o governo começa a financiar o déficit por meio da emissão desses títulos, fazendo com que a evolução da dívida fique atrelada à taxa de câmbio e sua flutuação, havendo aumento da dívida quando há desvalorização cambial.

Segundo Pedras (2009), o endividamento, em 1990, era composto praticamente por Letras Financeiras do Tesouro (LTFs), e, com um prazo médio de apenas cinco meses, a inflação atingiu $1000 \%$ ao ano, tendo o déficit primário atingido $1 \%$ do PIB no ano anterior. Após o plano real, o governo buscou melhorar substancialmente a composição da dívida e teve grande avanço com relação à estabilidade, porém em termos de efeitos sobre a composição da dívida não aconteceu como o esperado.

A partir de 1999, o Brasil voltou a emitir títulos indexados a índices de preços (IGP-M), havendo um esforço no sentido de obter contínua melhoria no perfil da dívida, tanto em termos de prazo quanto em qualidade de composição, objetivando reduzir a participação de títulos indexados à taxa de câmbio selic, o que vem acontecendo com sucesso desde 2003 (PEDRAS, 2009).

A tentativa de conter os gastos públicos ocorrida no Brasil também pode ser vista na União Europeia, onde diversos países se uniram e criaram a Comunidade Econômica Europeia com o objetivo de promover a estabilidade 
econômica.

Nesse contexto, o Brasil criou a LRF (de 04/05/00), que, segundo Mello et al. (2005), estabelece normas de finanças públicas relacionadas à gestão fiscal, com o objetivo maior de controlar o avanço do endividamento, fixando regras e limites.

\subsection{Limites da Dívida Pública}

A dívida pública brasileira, no que tange aos seus limites, é regulamentada pelo Senado Federal mediante resoluções.

A Resolução n. ${ }^{\circ} 78$, de 1998 , estabelece no art. $6^{\circ}$ que as operações de crédito interno e externo dos Estados, do Distrito Federal, dos Municípios e suas respectivas autarquias e fundações observarão simultaneamente os seguintes limites: II - o dispêndio anual máximo com amortizações, juros e demais encargos de todas as operações de crédito não poderá exceder a 13\% (treze por cento) da Receita Líquida Real (RLR), sendo essa receita realizada nos doze meses anteriores ao mês imediatamente anterior àquele em que se estiver apurando; III - o saldo total da dívida não poderá superar valor equivalente ao dobro da RLR anual para pleitos analisados no ano de 1998, decrescendo essa relação à base de um décimo por ano, até atingir valor equivalente a uma RLR anual para pleitos analisados no ano de 2008 em diante (BRASIL, 1998).

A Resolução $n^{\circ}$ 43, de 2001, em seu art. 4º define a Receita Corrente Líquida (RCL) como o somatório das receitas tributárias, de contribuições, patrimoniais, industriais, agropecuárias, serviços, de transferências correntes e outras receitas também correntes, deduzidas: II - nos Estados e nos Municípios, a contribuição dos servidores para custeio do seu sistema de previdência e assistência social e as receitas provenientes da compensação financeira citada no inciso $9^{\circ}$ do art. 201 da Constituição Federal. $\mathrm{O}$ art. $7^{\circ}$ dessa mesma Resolução estabelece que as operações de crédito interno e externo dos Estados, do Distrito Federal, e dos Municípios observarão os seguintes limites: II - o comprometimento anual com amortizações, juros e demais encargos da Dívida Pública Consolidada não poderá exceder a
$11,5 \%$ (onze inteiros e cinco décimos de inteiro) da RCL (BRASIL, 2001c).

Além disso, a Resolução n. ${ }^{\circ} 40$, de 2001 , no art. $1^{\circ}$, estabelece as seguintes definições: III - Dívida Pública Consolidada (DPC) - montante total, apurado sem duplicidade, das obrigações financeiras, inclusive as decorrentes das emissões de títulos, do Estado, do Distrito Federal e dos Municípios, assumidas em virtudes de leis, contratos, convênios ou tratados e da realização de operações de crédito para amortização em operações em prazo superior a 12 (doze) meses, dos precatórios judiciais emitidos a partir de 05 de maio de 2000 e não pagos durante o período de execução do orçamento em que houverem sido incluídas, e das operações de crédito, que, embora de prazo inferior a prazo de 12 (doze) meses, tenham constado como receitas no orçamento. Estabelece também, no art. $3^{\circ}$, que a Dívida Consolidada Líquida (DCL) dos Estados, do Distrito Federal e dos Municípios, ao final do décimo quinto exercício financeiro contando a partir do ano de publicação desta Resolução, não poderá exceder respectivamente a: II - no caso dos municípios 1,2 (um inteiro e dois décimos) vezes a RCL, definida na forma do art. $2^{\circ}$. Fica estabelecido também no art. $4^{\circ}$ que no período compreendido entre a data de publicação desta resolução e o final do décimo quinto exercício a que se refere no art. $3^{\circ}$, serão observadas as seguintes colocações: I - o excedente em relação aos limites previstos no art. $3^{\circ}$ apurados ao final do exercício do ano da publicação desta Resolução deverá ser reduzido, no mínimo, à proporção de 1/15 (um quinze avos) a cada exercício financeiro (BRASIL, 2001b).

\subsection{Indicadores da Dívida Pública}

Através dos indicadores econômicos e contábeis podem-se verificar os impactos de determinada ação na gestão pública e a correção de eventuais desvios. Neste trabalho, os indicadores permitiram fazer comparações entre os níveis de endividamentos dos Municípios Potiguares, e estimar e relacionar quanto a Dívida e os encargos causados por ela comprometem a receita deles.

Para avaliar a situação do endividamento dos Municípios e mensurar se eles têm obedecido aos limites impostos 
A Lei de Responsabilidade Fiscal (LRF) e o impacto sobre o endividamento dos municípios potiguares

pela LRF, foram utilizados quatro indicadores, conforme o Quadro 1. O primeiro indicador mede a relação entre a DCL e a RCL e aponta quanto da RCL está comprometida com o montante da Dívida Líquida, e o segundo mede a relação entre os Encargos da Dívida Consolidada (EDC) e a RCL e indica a parcela da RCL comprometida com a amortização da Dívida Consolidada.

A escolha desses indicadores se justifica porque ambos são estabelecidos pela própria LRF no relatório de Gestão Fiscal e são utilizados oficialmente como referência de endividamento dos Estados e Municípios.

Além disso, com o objetivo de ampliar a qualidade da análise e o número de indicadores de endividamento, foram utilizados, juntamente com os previsto na LRF, os sugeridos por Matias e Campello (2000), a saber:

Participação dos encargos da dívida fundada nas receitas correntes (soma de todas as receitas tributárias, de contribuições, patrimoniais, agropecuárias, industriais, de serviços, as transferências correntes e outras receitas correntes) $=$ amortização da dívida fundada (ADF) dividida pelas receitas correntes (RC): indica a parcela das receitas correntes comprometidas com a amortização da dívida fundada.

Participação do passivo financeiro a descoberto nas receitas orçamentárias $=$ passivo financeiro $(\mathrm{PF})$ menos ativo financeiro (AF) dividido pelas receitas correntes (RC): verifica o número de períodos em que o endividamento total seria quitado frente às disponibilidades orçamentárias (MATIAS; CAMPELLO, 2000, p. 238-239).

Assim, no Quadro 1, podem-se verificar os indicadores e os limites de endividamento definidos pela LRF e propostos por Matias e Campello.

Quadro 1 - Resumo dos Indicadores de

\begin{tabular}{|c|c|c|}
\hline \multicolumn{3}{|c|}{ Endividamento } \\
\hline Indicadores & Fórmulas & Limites \\
\hline Relaçào entre a D'vivida Consolidada Liquida e a Receita Corrente Liquida & DCLRCL & 2001 a $2009=1,2 x R C L$ \\
\hline Relaçà entre os Encargos D'vida Consolidada e Receita Corente Líquida & EDCRCL & $2001=13 \%$ e 2002 a $2009=11,5 \%$ \\
\hline Participaçàa dos encargos da Divida fundada nas receitas correntes & ADF/RC & \\
\hline 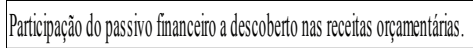 & $(\mathrm{PF}-\mathrm{AF}) / \mathrm{RC}$ & \\
\hline
\end{tabular}

Fonte: Elaborado pelos autores

\subsection{Pesquisas Empíricas}

Há vários estudos realizados considerando aspectos relacionados à LRF e ao endividamento. Para melhor ilustrar essa relação e proporcionar uma fonte de informações para comparar com a pesquisa proposta, segue abaixo a relação de alguns estudos:

- Fioravante, Pinheiro e Vieira (2006) avaliaram o impacto da LRF sobre as finanças públicas municipais. Para essa análise foram traçados dois cenários, um "antes" e outro "depois" da Lei, com base nos quais se comparou o comportamento dos Municípios no tocante às políticas de gastos e de endividamento. Os resultados mostraram que, no caso da despesa com pessoal como proporção da receita corrente líquida, a imposição do limite de $60 \%$ estimulou o aumento dessa despesa para a maioria dos municípios que apresentava gastos muito inferiores ao teto determinado. No entanto, a minoria que ultrapassava esse teto se ajustou. Para o indicador de endividamento, a Lei gerou um efeito controlador para o pequeno número de municípios que ultrapassava o limite imposto, segundo os resultados encontrados. No entanto, os municípios que não se ajustaram aumentaram sua participação na dívida agregada de todos os municípios. Portanto, nesse caso, notaram-se dois efeitos: um controle da dívida de alguns municípios e uma concentração de endividamento de outros que não foram controlados.

- Mello et al. (2006) propuseram uma função para representar a situação do endividamento dos Estados Brasileiros. Para cumprir o objetivo, foram selecionados nove indicadores de endividamento, calculados para o período de 2001 a 2003. Em seguida, aplicou-se a técnica estatística análise discriminante. Considerando os resultados, concluiu-se que as variáveis que melhor representam a situação de endividamento dos Estados Brasileiros foram: Despesa Corrente dividida pela Receita Corrente Líquida; Passivo Financeiro menos o Ativo Financeiro dividido pela Receita Corrente; Despesa Total dividida pela Receita Operacional. Dessa forma, demonstrou-se que o endividamento não se explica por um único indicador, sendo necessário um conjunto de indicadores reunidos estatisticamente.

- Costa (2008) discutiu os efeitos da LRF para a redução do endividamento dos 26 Municípios brasileiros capitais de estado, a partir de sua implementação em 2000. Os dados utilizados cobrem o período de 1999 
a 2004. Foi utilizada a regressão com dados em painel utilizando as variáveis: Endividamento (dependente); LRF e Eleição (independentes); PIB Per Capita, Risco Brasil e Taxa Real de Juros (controle). Os resultados indicam que a LRF não se confirma como um mecanismo institucional para a redução do endividamento público e que há evidências de que o limite de endividamento estabelecido pela LRF estava muito acima dos resultados médios encontrados, ou seja, o teto do endividamento estava bem acima do endividamento corrente das cidades brasileiras, não impondo nenhuma restrição à dívida corrente das capitais.

- Macedo e Corbari (2009) analisaram se a LRF, como mecanismo de restrição fiscal, influenciou no padrão de endividamento praticado pelos municípios brasileiros com mais de 100 mil habitantes, no período de 1998 a 2006. Para atingir tal fim, foram construídos dois modelos econométricos. O primeiro verificou se houve alteração da influência das variáveis de gestão financeira sobre o endividamento ao longo do tempo, em que os resultados indicaram que as variáveis Estrutura de Capital e Endividamento Defasado alteram seu padrão de influência sobre o endividamento público. O segundo avaliou se a alteração do padrão de influência das variáveis de gestão financeira sobre o endividamento estava relacionada com a introdução da LRF. Nesse caso, os resultados indicaram que a LRF alterou o padrão de influência sobre o endividamento de Estrutura de Capital e Endividamento Defasado, variáveis que possuem maior poder de predição sobre o endividamento público.

\subsection{O Caso das Finanças Públicas Potiguares}

De acordo com Silva e Sousa (2002), no período de 1997 a 2001, o Rio Grande do Norte era um dos estados que exibiram menor grau de endividamento e que o nível de endividamento não é explicado apenas pelas condições econômicas, pois entre os estados mais endividados encontravam-se tanto os de grande representação econômica no conjunto da federação como os com menor expressão na economia nacional.

Mais recentemente, o estudo realizado por Silva (2009), feito com o objetivo de analisar o comportamento dos diversos Municípios Potiguares à luz da LRF, no período de 1997 a 2005, chegou às seguintes conclusões:

- despesa com pessoal, com a implantação da LRF, apresenta retornos significativos maiores diante da receita corrente líquida, comparativamente ao período anterior à lei;

- alcance de um equilíbrio tendencial nas contas públicas municipais, além de um ritmo de crescimento sustentável e em condições estáveis, mostrando que a LRF foi efetiva; - arrecadação não apresentou redução e, além disso, ocorreu tendências de redução nos déficits públicos municipais;

- diferenciação comportamental entre os municípios mais ou menos dinâmicos, pois os mais dinâmicos exibiram um crescimento econômico mais sustentável durante o período visto.

Entretanto, segundo Fioravante, Pinheiro e Vieira (2006), ao observarem o comportamento do endividamento, verificaram que o Estado do Rio Grande do Norte aumentou a proporção de endividamento entre o período de 1998 a 2000 e 2001 a 2004, ou seja, depois da implantação da LRF a relação dívida consolidada líquida e receita

corrente líquida aumentou.

\section{METODOLOGIA}

Para a concretização deste estudo, utilizou-se como técnica de trabalho uma pesquisa empírico-analítica, que segundo Martins (2002, p. 34), “[...] são abordagens que apresentam em comum a utilização de técnicas de coleta, tratamento e análise de dados marcadamente quantitativos. Privilegiam estudos práticos. Suas propostas têm caráter técnico, restaurador e incrementalista”.

Os dados utilizados para calcular os indicadores, destacados no Quadro 1, foram obtidos nos relatórios contábeis e financeiros do banco de dados da Secretaria do Tesouro Nacional (Finanças Brasil). O trabalho de pesquisa consiste em comparar os resultados dos indicadores dos Municípios Potiguares, no período de 1998 à 2003, para verificar se ocorreram mudanças significativas no endividamento desses Municípios após a implantação da LRF. 
$\mathrm{O}$ período estabelecido se justifica pelo fato de que a LRF foi publicada em maio de 2000, mas teve reflexos a partir de 2001, logo tem-se 3 anos antes e 3 anos depois de sua implantação, fato primordial para a comparação dos resultados.

A amostra estabelecida era inicialmente constituída de todos os Municípios do Rio Grande do Norte (167). Porém 86 municípios tiveram de ser excluídos por falta de dados, o que pode ser explicado pela não inclusão dos dados, por parte dos Municípios, no sistema de coleta de dados contábeis de Estados e Municípios. Dessa forma, ficaram fora da análise os seguintes municípios: Afonso Bezerra, Almino Afonso, Alto do Rodrigues, Campo Grande, Baía Formosa, Barcelona, Bento Fernandes, Bom Jesus, Brejinho, Caiçara do Rio do Vento, Campo Redondo, Canguaretama, Carnaubais, Ceará-Mirim, Cerro Corá, Coronel Ezequiel, Doutor Severiano, Parnamirim, Equador, Espírito Santo, Felipe Guerra, Florânia, Francisco Dantas, Galinhos, Governador DixSept Rosado, Grossos, Ielmo Marinho, Ipanguaçu, Jaçanã, Jandaíra, Januário Cicco, Japi, João Câmara, João Dias, Jucurutu, Jundiá, Lagoa D’anta, Lagoa de Pedras, Lagoa de Velhos, Lagoa Salgada, Lajes, Lajes Pintadas, Macaíba, Montanhas, Monte Alegre, Monte das Gameleiras, Nísia Floresta, Nova Cruz, Paraná, Espírito Santo do Oeste, Rio do Fogo, Passagem, Santa Maria, Pedra Grande, Pedra Preta, Pedro Avelino, Pendências, Pilões, Poço Branco, Portalegre, Porto do Mangue, Pureza, Rafael Fernandes, Rafael Godeiro, Riacho da Cruz, Ruy Barbosa, Santana do Matos, São Bento do Norte, São Bento do Trairi, São Francisco do Oeste, São José de Mipibu, São José do Campestre, São Paulo do Potengi, São Pedro, Senador Elói de Souza, Serra do Mel, Sitio Novo, Taboleiro Grande, Tenente Laurentino Cruz, Tibau, Tibau do Sul, Triunfo Potiguar, Upanema, Vera Cruz, Viçosa e Vila Flor.

Utilizou-se o teste de hipótese de diferenças de médias para observações emparelhadas, que, de acordo com Bussab e Morettin (1987, p. 283), “[...] é usado quando as observações de duas amostras são feitos do mesmo individuo, medindo suas características antes e depois dele ser submetido a um tratamento".

Para tal, estabeleceram-se as seguintes hipóteses estatísticas:

$\mathrm{H}_{0}$ : End. Antes da LRF - End. Depois da LRF $=0$

$\mathrm{H}_{1}$ : End. Antes da LRF - End. Depois da LRF $\neq 0$

Sendo "End. Antes da LRF" igual à média do indicador de endividamento calculado antes da LRF, ou seja, de 1998 a 2000, e "End. Depois da LRF" igual à média do indicador de endividamento calculado depois da LRF, ou seja, de 2001 a 2003.

A hipótese nula $\left(\mathrm{H}_{0}\right)$ infere que a média do indicador calculado antes da LRF é igual à média do mesmo indicador calculado depois da LRF.

A hipótese alternativa $\left(\mathrm{H}_{1}\right)$ infere que a média do indicador calculado antes da LRF é diferente da média do mesmo indicador calculado depois da LRF. Portanto, o objetivo é rejeitar a hipótese nula porque as médias dos indicadores são iguais.

Para aplicar o teste de hipótese de diferenças de médias para observações emparelhadas em cada um dos indicadores de endividamento descrito no Quadro 1, “[...] é exigido, sendo esse um teste paramétrico, os pressupostos básicos de que as variáveis tenham uma distribuição normal e que as variâncias populacionais sejam homogêneas" (MAROCO, 2003, p. 111).

Dessa forma, para verificar o pressuposto da normalidade foi utilizado o teste de Kolmogorov-Smirnov (K-S), que, segundo Maroco (2003), é apropriado para tal objetivo, sendo produzido pelo software SPSS $\AA$ (utilizado como ferramenta para execução dos testes estatísticos deste trabalho). Ambos os testes serão aplicados a um nível de significância de 0,05 .

O pressuposto da normalidade, entretanto, não foi atendido, por isso a alternativa foi aplicar o teste não paramétrico de Wilcoxon.

Segundo Maroco (2003), o teste Wilcoxon é uma alternativa ao teste $t$ de Student para comparar duas médias populacionais com base em amostras emparelhadas, quando uma distribuição não é normal. Além da informação de cada par, o teste de Wilcoxon 
leva em consideração a magnitude da diferença dentro dos pares.

Para completar a resposta do objetivo deste trabalho, deve-se demonstrar se os Municípios Potiguares cumpriram com os limites de endividamento estabelecidos na LRF e fixados pelo Senado Federal. Para tal, foram analisados os resultados dos indicadores DCL/RCL e EDC/RCL nos anos de 2001 a 2009 e comparados com os limites descritos no Quadro 1.

Neste caso, a amostra estabelecida era inicialmente constituída de todos os Municípios do Rio Grande do Norte (167), porém 45 deles tiveram de ser excluídos por falta de dados. Ficaram fora da análise os seguintes municípios: Barcelona, Bento Fernandes, Caiçara do Norte, Coronel Ezequiel, Felipe Guerra, Galinhos, Governador Dix-Sept Rosado, Grossos, Guamaré, Ielmo Marinho, Jaçanã, Jandaíra, Janduís, Japi, Jardim de Angicos, João Câmara, José da Penha, Jundiá, Lagoa de Pedras, Lagoa de Velhos, Lagoa Salgada, Lajes Pintadas, Macau, Monte das Gameleiras, Espírito Santo do Oeste, Rio do Fogo, Patu, Pedra Grande, Pedra Preta, Poço Branco, Pureza, Riachuelo, Rodolfo Fernandes, Tibau, São Bento do Norte, São Bento do Trairi, São Francisco do Oeste, São José do Campestre, São Miguel, Senador Elói de Souza, Serra do Mel, Serrinha, Sítio Novo, Tenente Ananias e Vila Flor.

\section{APRESENTAÇÃO E ANÁLISE DE RESULTADOS}

Inicialmente, para verificar se ocorreram mudanças significativas no endividamento desses Municípios após a implantação da LRF, a amostra foi submetida ao teste de normalidade, porém, como pode ser visto na Tabela 1 , todos os indicadores apresentam o nível se significância menor que 0,05 , não possuindo, portanto, uma distribuição normal.
Tabela 1 - Teste de Normalidade

\begin{tabular}{|l|c|c|c|c|}
\hline \multicolumn{2}{|c|}{ Indicadores } & \multicolumn{3}{|c|}{ Kolmogorov-Smirnov } \\
\cline { 3 - 5 } & Antes LRF & 0,116 & 81 & 0,008 \\
\hline \multirow{2}{*}{ DCL/RCL } & Depois LRF & 0,150 & 81 & 0,000 \\
\hline \multirow{2}{*}{ EDC/RCL } & Antes LRF & 0,351 & 81 & 0,000 \\
\cline { 2 - 5 } & Depois LRF & 0,422 & 81 & 0,000 \\
\hline \multirow{2}{*}{ ADF/RC } & Antes LRF & 0,352 & 81 & 0,000 \\
\cline { 2 - 5 } & Depois LRF & 0,422 & 81 & 0,000 \\
\hline \multirow{2}{*}{ (PF-AF)/RC } & Antes LRF & 0,187 & 81 & 0,000 \\
\cline { 2 - 5 } & Depois LRF & 0,142 & 81 & 0,000 \\
\hline
\end{tabular}

Fonte: extraída do software SPSS ${ }^{\circledR}$ e adaptada pelos autores.

Tendo em vista que os indicadores não possuem uma distribuição normal, pressuposto para a aplicação do teste t de Student para amostras emparelhadas, a alternativa foi aplicar o teste não paramétrico de Wilcoxon.

Analisando a Tabela 2, nota-se que os indicadores DCL/ $\mathrm{RCL}, \mathrm{EDC} / \mathrm{RCL}, \mathrm{ADF} / \mathrm{RC}$ e $\mathrm{PF}-\mathrm{AF} / \mathrm{RC}$ possuem $p$-value menor que o nível de significância de 0,05 ; dessa forma, rejeitam-se as hipóteses que as médias desses indicadores são iguais, aceitando que são diferentes.

Tabela 2 - Teste de Wilcoxon para médias emparelhadas

\begin{tabular}{|l|c|c|c|c|}
\hline Teste de Wilcoxon & DCLRCL & EDC/RCL & ADF/RC & (PF-AF)/RC \\
\hline$Z$ & $-2,180$ & $-2,485$ & $-2,470$ & $-7,110$ \\
\hline Asymp. Sig. (2-tailed) & 0,029 & 0,013 & 0,014 & 0,000 \\
\hline
\end{tabular}

Fonte: extraída do software SPSS $^{\circledR}$ e adaptada pelos autores.

Considerando que as médias dos indicadores são diferentes, é possível identificar, na Tabela 3, quantos municípios tiveram aumento e quantos tiveram redução no endividamento após a implantação da LRF.

Tabela 3 - Rank estabelecido pelo teste Wilcoxon para médias emparelhadas

\begin{tabular}{|l|l|c|c|c|}
\hline Indicador & \multicolumn{1}{|c|}{ Ranks } & N & $\begin{array}{c}\text { Média dos } \\
\text { Ranks }\end{array}$ & $\begin{array}{c}\text { Soma dos } \\
\text { Ranks }\end{array}$ \\
\hline \multirow{5}{*}{ DCL/RCL } & Ranks negativos & 51 & 41 & 2075 \\
\cline { 2 - 5 } & Ranks positivos & 29 & 40 & 1166 \\
\cline { 2 - 5 } & Empates & 1 & & \\
\cline { 2 - 5 } EDC/RCL & Total & 81 & & \\
\hline \multirow{5}{*}{ ADF/RC } & Ranks negativos & 27 & 18 & 491 \\
\cline { 2 - 6 } & Ranks positivos & 9 & 20 & 176 \\
\cline { 2 - 6 } & Empates & 45 & & \\
\cline { 2 - 6 } & Total & 81 & & \\
\cline { 2 - 6 } & Ranks negativos & 27 & 18 & 490 \\
\cline { 2 - 6 } & Ranks positivos & 9 & 20 & 177 \\
\cline { 2 - 6 } & Empates & 45 & & \\
\hline \multirow{5}{*}{ Potal } & Ranks negativos & 9 & 17 & 151 \\
\cline { 2 - 6 } & Ranks positivos & 72 & 44 & 3171 \\
\cline { 2 - 6 } & Empates & 0 & & \\
\cline { 2 - 6 } & Total & 81 & & \\
\hline
\end{tabular}

Fonte: extraída do software SPSS ${ }^{\circledR}$ e adaptada pelos autores. 
A Lei de Responsabilidade Fiscal (LRF) e o impacto sobre o endividamento dos municípios potiguares

Conforme resultado dos ranks do indicador DCL/RCL (Tabela 3), apenas 29 municípios (ranks positivos) dos 81 analisados tiveram variação positiva do endividamento, ou seja, 51 municípios (ranks negativos) tiveram redução do comprometimento da RCL no montante das dívidas líquidas, correspondendo a $63 \%$, e em apenas um município houve empate.

Quanto aos indicadores EDC/RCL e ADF/RC, apenas 9 dos 81 municípios analisados tiveram variação positiva nessas amortizações, ou seja, 27 municípios tiveram redução na amortização da dívida consolidada e na fundada, respectivamente, correspondendo a $33 \%$, e em 45 ocorreu empate.

Além disso, o resultado do indicador $(\mathrm{PF}-\mathrm{AF}) / \mathrm{RC}$ evidenciou que 72 dos 81 municípios analisados tiveram variação positiva, ou seja, apenas 9 municípios (11\%) tiveram redução no número de períodos em que o endividamento seria quitado.

Na sequência, ao verificar se os municípios potiguares cumpriram com os limites de endividamento estabelecidos na LRF e fixados pelo Senado Federal, nos anos de 2001 a 2009, com base no resultado do indicador DCL/ RCL, constatou-se que apenas o município de Timbaúba dos Batistas, em 2001, excedeu o limite de 1,2, tendo um índice de 1,27. Quanto ao indicador EDC/RCL, todos os municípios analisados cumpriram com o limite.

Portanto, observou-se que todos os municípios da amostra cumprem com os limites de endividamento, fato ilustrado na Tabela 4, onde consta uma relação dos 30 municípios com maior endividamento médio, considerando o período de 2001 a 2009.
Tabela 4 - Relação dos 30 Municípios com maior endividamento

\begin{tabular}{|c|l|c|c|}
\hline Classificação & \multicolumn{1}{|c|}{ Municípios } & $\begin{array}{c}\text { DCL/RCL média } \\
\text { de 2001 a 2009 }\end{array}$ & $\begin{array}{c}\text { Poulação de } \\
2009\end{array}$ \\
\hline $1^{\circ}$ & São Tomé & 0,987 & 11.501 \\
\hline $2^{\circ}$ & Extremoz & 0,934 & 22.751 \\
\hline $3^{\circ}$ & Campo Grande & 0,921 & 9.203 \\
\hline $4^{\circ}$ & Lajes & 0,921 & 10.865 \\
\hline $5^{\circ}$ & Marcelino Vieira & 0,915 & 8.331 \\
\hline $6^{\circ}$ & Itaja & 0,905 & 6.629 \\
\hline $7^{\circ}$ & Caico & 0,904 & 63.006 \\
\hline $8^{\circ}$ & Coronel João Pessoa & 0,903 & 4.993 \\
\hline $9^{\circ}$ & Almino Afonso & 0,903 & 5.071 \\
\hline $10^{\circ}$ & Encanto & 0,903 & 5.365 \\
\hline $11^{\circ}$ & Riacho de Santana & 0,900 & 4.437 \\
\hline $12^{\circ}$ & Jardim de Piranhas & 0,900 & 14.347 \\
\hline $13^{\circ}$ & Carnaubais & 0,900 & 9.712 \\
\hline $14^{\circ}$ & Luis Gomes & 0,897 & 10.144 \\
\hline $15^{\circ}$ & Cerro Cora & 0,897 & 11.235 \\
\hline $16^{\circ}$ & Canguaretama & 0,896 & 30.541 \\
\hline $17^{\circ}$ & Itaú & 0,896 & 5.999 \\
\hline $18^{\circ}$ & Rafael Godeiro & 0,896 & 3.251 \\
\hline $19^{\circ}$ & Ceara-Mirim & 0,894 & 67.869 \\
\hline $20^{\circ}$ & São José de Mipibu & 0,893 & 38.404 \\
\hline $21^{\circ}$ & Alexandria & 0,893 & 14.151 \\
\hline $22^{\circ}$ & Rafael Fernandes & 0,890 & 4.797 \\
\hline $23^{\circ}$ & Nova Cruz & 0,888 & 36.561 \\
\hline $24^{\circ}$ & Pedro Avelino & 0,885 & 7.559 \\
\hline $25^{\circ}$ & Natal & 0,884 & 806.203 \\
\hline $26^{\circ}$ & Santo Antonio & 0,884 & 22.071 \\
\hline $27^{\circ}$ & Florania & 0,884 & 8.487 \\
\hline $28^{\circ}$ & Taboleiro Grande & 0,883 & 2.380 \\
\hline $29^{\circ}$ & Bom Jesus & 0,883 & 8.725 \\
\hline $30^{\circ}$ & Triunfo Potiguar & 0,881 & 3.327 \\
\hline \hline
\end{tabular}

Fonte: Elaborada pelos autores.

Ao analisar a Tabela 4, observa-se que o município de São Tomé, com população, em 2009, de 11.501 habitantes, é o que possui o maior índice de endividamento médio $(0,987)$, abaixo do limite de 1,2 , enquanto o município de Natal, o mais populoso do estado, está na posição $25^{\circ}$, com um endividamento médio de 0,884 .

Nota-se que entre os 30 municípios com maior endividamento médio não é possível verificar uma correlação entre o endividamento e o tamanho do município (população), fato confirmado com o teste de correlação de Pearson (Tabela 5), considerando todos os municípios da amostra.

Tabela 5 - Correlação de Pearson

\begin{tabular}{|c|c|c|}
\hline & & População de 2008 \\
\hline \multirow{2}{*}{$\begin{array}{c}\text { DCL/RCL - média } \\
\text { de 2001 a } 2009\end{array}$} & Correlação & $-0,008$ \\
\cline { 2 - 3 } & Sig. (2-tailed) & 0,932 \\
\cline { 2 - 3 } & $\mathrm{N}$ & 122 \\
\hline
\end{tabular}

Fonte: extraída do software SPSS $^{\circledR}$ e adaptada pelos autores. 
Para melhor entender os resultados encontrados, fez-se um comparativo com os achados do trabalho desenvolvido por Machado (2010), a qual fez essa mesma pesquisa para os municípios paranaenses.

Enquanto $63 \%$ dos municípios potiguares reduziram seu endividamento depois da implantação da LRF, nos municípios paranaenses essa percentagem foi de 93\%. Com relação à redução dos encargos da dívida, apenas 33\% dos municípios potiguares o fizeram, já nos paranaenses isso ocorreu em $81 \%$. O mais destoante ocorreu com o número de períodos em que o endividamento seria quitado, pois em $89 \%$ dos municípios potiguares esse período aumentou, tendo ocorrido o mesmo em apenas $14 \%$ dos municípios paranaenses.

Com relação ao cumprimento dos limites, percebe-se que os municípios potiguares e paranaenses estão abaixo do estabelecido, mas os potiguares estão mais endividados. Isso pode ser confirmado quando se observa a média do endividamento médio do período de 2001 a 2009, de 0,86 para os potiguares e de 0,81 para os paranaenses.

O resultado dessa comparação leva a alguns questionamentos, mas a questão principal reside em saber por que os municípios potiguares são mais endividados do que os paranaenses. Uma resposta é a utilização do endividamento como forma de realização de investimentos (pagamento de despesas realizadas), conforme citado por Pedras (2009). Mas para que isso seja verdadeiro é necessário que tais investimentos reflitam em um melhor desenvolvimento econômico e/ou social.

Por isso, optou-se em comparar os indicadores de endividamento com indicadores disponíveis que representam o desenvolvimento econômico e social, nesse caso, o PIB per capita e o Índice Firjan de Desenvolvimento Municipal - IFDM. Segundo Firjan (2010), o IFDM nasceu em resposta à necessidade de se monitorar anualmente o desenvolvimento socioeconômico dos Municípios. O índice contempla três esferas (todas com peso igual): emprego\&renda, educação e saúde.

Conforme se pode observar na Tabela 6, o indicador PIB per capita médio, calculado para o período de 2002 a
2007 (período disponível para os municípios), não tem correlação estatisticamente significativa com os indicadores de endividamento (DCL/RCL e EDC/RCL, média de 2002 a 2007).

Tabela 6 - Correlação de Pearson

\begin{tabular}{|c|c|c|c|}
\hline & & $\begin{array}{c}\text { DCLRCL - média } \\
\text { de 2002 a 2007 }\end{array}$ & $\begin{array}{c}\text { EDC/RCL - média } \\
\text { de 2002 a 2007 }\end{array}$ \\
\hline \multirow{3}{*}{$\begin{array}{c}\text { PIB per capita - média de } \\
2002 \text { a } 2007\end{array}$} & Correlação & $-0,008$ & 0,108 \\
\cline { 2 - 4 } & Sig. (2-tailed) & 0,931 & 0,237 \\
\cline { 2 - 4 } & $\mathrm{N}$ & 122 & 122 \\
\hline
\end{tabular}

Fonte: extraída do software SPSS $^{\circledR}$ e adaptada pelos autores.

Esse fato se repete na correlação dos indicadores de endividamento com o IFDM, mesmo sendo a média de um período diferente (2006 e 2007, já que o IFDM está disponível para apenas esse período), pois também não se encontrou tal correlação.

Tabela 7 - Correlação de Pearson

\begin{tabular}{|c|c|c|c|}
\hline & & $\begin{array}{c}\text { DCLRCL média de } \\
2002 \text { a } 2007\end{array}$ & $\begin{array}{c}\text { EDC/RCL média de } \\
\text { 2002 a } 2007\end{array}$ \\
\hline \multirow{3}{*}{$\begin{array}{c}\text { IFDM - média de 2006 a } \\
2007\end{array}$} & Correlação & $-0,020$ & 0,159 \\
\cline { 2 - 4 } & Sig. (2-tailed) & 0,828 & 0,080 \\
\cline { 2 - 4 } & $\mathrm{N}$ & 122 & 122 \\
\hline
\end{tabular}

Fonte: extraída do software SPSS $^{\circledR}$ e adaptada pelos autores.

Não foi possível, portanto, confirmar se o endividamento foi utilizado como forma de investimento, pois as correlações não se mostraram estatisticamente significativas.

\section{CONCLUSÃO}

Verificou-se, com esta pesquisa, a situação financeira dos Municípios Potiguares após a implantação da LRF, no que diz respeito à redução do endividamento e ao cumprimento dos seus limites.

Pode-se concluir que em $63 \%$ dos municípios analisados houve redução significativa no endividamento, que em $33 \%$ houve redução no pagamento dos encargos da dívida e que em $11 \%$ houve redução no número de períodos de pagamento.

Com relação aos limites de endividamento concluise que os municípios pesquisados estão de acordo com os limites impostos na LRF, não excedendo 1,2 (um inteiro e dois décimos) vezes a Receita Corrente 
Líquida e não comprometendo a RCL em mais de $11,5 \%$ com amortização, juros e demais encargos da Dívida Consolidada Liquida.

Comparando esses achados com os de Fioravante, Pinheiro e Vieira (2006), percebe-se alguma semelhança entre eles, pois em ambos a LRF gerou um efeito de controle da dívida de alguns municípios e uma concentração de endividamento de outros que não foram controlados.

Portanto, as evidências indicam que a LRF pode estar cumprindo com seu objetivo de controlar o avanço do endividamento dos Municípios da amostra, com a fixação de regras e limites, mesmo contrariando os achados de Costa (2008), que indicam que a LRF não se confirma como um mecanismo institucional para a redução do endividamento público das capitais brasileiras. Talvez tal fato possa ser explicado pela diferença entre as amostras pesquisadas.

Percebe-se, também, que com os dados de anos anteriores à normatização da LRF, os índices obtidos, em sua maioria, já estavam de acordo com o percentual estabelecido pela Lei.

Observou-se, ainda, que não existe correlação estatisticamente significativa entre endividamento dos Municípios e número de habitantes (população), ou seja, não se pode concluir que os municípios com mais dívidas são os mais populosos ou vice-versa.

Entretanto, ao comparar os resultados encontrados dos municípios potiguares com os dos paranaenses, observouse que os potiguares são mais endividados. Mas não foi possível confirmar por que existe essa diferença.

Cabe destacar que este trabalho foi desenvolvido com algumas limitações, como: amostra definida intencionalmente (por conveniência), a qual deveria ser constituída por todos os municípios potiguares, mas, em virtude da falta de dados, muitos foram excluídos; uso de apenas 3 anos antes e 3 anos depois da implantação da LRF, devido ao fato de a Lei ter começado a ser praticada a partir de 2001 e de não existirem informações disponíveis no ano de 1997, impossibilitando uma comparação com um período maior; uso de teste estatístico não paramétrico, uma vez que as observações não seguem uma distribuição normal; não verificação de todas as possíveis causas de os municípios potiguares terem um endividamento médio maior que, por exemplo, os paranaenses, isso por não fazer parte do objetivo deste trabalho.

Sugere-se, para futuras pesquisas, um estudo mais completo, abrangendo todos os Municípios brasileiros, podendo haver separação por regiões, e comparando o endividamento com um número maior de indicadores de desenvolvimento econômico e social.

Conclui-se que a LRF tem sido eficaz quanto à possibilidade de frear possíveis exageros por parte das administrações municipais, através de premissas como a transparência e o planejamento na condução das contas públicas, fazendo com que as informações cheguem de forma detalhada à população por meio de relatórios fiscais.

\section{REFERÊNCIAS}

BRASIL. Banco Central do Brasil. Nota para a imprensa - 29.9.2010, 2010.

Política Fiscal. Disponível em: <http:/www.bcb.gov.br/ htms/notecon3-p.asp?idioma $=\mathrm{P}>$. Acesso em: 25 out. 2010 .

Controladoria Geral da União. Resolução de n. $^{\mathbf{0}}$ 78, 1998. Disponível em: <http://www. cgu.gov.br/AreaAuditoriaFiscalizacao/Arquivos/ FinanciamentoExternoECooperacao/Legislacao/ Resolucao78_1998.asp>. Acesso em: 17 jun. 2010.

Lei Complementar $\mathbf{n}^{\mathbf{0}} \mathbf{1 0 1}$, de 4 de maio de 2001 (Lei de Responsabilidade Fiscal), 2001a. Estabelece normas de finanças públicas voltadas para a responsabilidade na gestão fiscal e dá outras providências.

. Tesouro Nacional. Resolução n. ${ }^{\circ}$ 40, 2001 b. Disponível em: <http://www.tesouro.fazenda.gov.br/ legislacao/download/contabilidade/ResSF40_2001.pdf >. Acesso em: 17 jun. 2010. 
Tesouro Nacional. Resolução n. ${ }^{\circ}$ 43, 2001c. Disponível em: <http://www.tesouro. fazenda.gov.br/legislacao/download/contabilidade/ RSF43_2001consolidada.pdf>.Acesso em: 17 jun. 2010.

BUSSAB, Wilton O.; MORETTIN, Pedro A. Estatística Básica. 4 ed. São Paulo: Atual, 1987.

CGRN - CONTROLADORIA GERAL DO ESTADO DO RIO GRANDE DO NORTE. Informativo 19. Ano III, Fevereiro/1999. Disponível em: <http://www.control. rn.gov.br/informativos. asp.>. Acesso em: 25 nov. 2010.

COSTA, José Fernandes da. Reflexo da Lei de

Responsabilidade Fiscal no endividamento dos Municípios Capitais dos Estados Brasileiros. Dissertação de mestrado. Programa de Pós-Graduação em Ciências Contábeis da Fundação Instituto Capixaba de Pesquisas em Contabilidade, Economia e Finanças (FUCAPE), 2007.

COSTA, José Fernandes da. Reflexos da lei de responsabilidade fiscal no endividamento dos municípios brasileiros. $18^{\circ}$ Congresso Brasileiro de Contabilidade. Conselho Federal de Contabilidade. Gramado/RS, 2008. 24 a 28 de agosto de 2008.

DECAT, Eric. Municípios - Contabilizando prejuízos. Desafios do Desenvolvimento Ano 6 . Edição 47. Brasilia: IPEA. 19/02/2009. 2009 . pp. 56-62.Disponível em $<$ http://desafios.ipea.gov.br/index.php?option=com content $\&$ view $=$ article $\&$ id $=1208 \&$ catid $=28 \&$ Itemid $=39$ $>$ Acesso 09 de Junho de 2010

FIORAVANTE, Dea Guerra; PINHEIRO, Maurício Mota Saboya; VIEIRA, Roberta da Silva. Lei de Responsabilidade Fiscal e Finanças Públicas Municipais: impactos sobre despesas com pessoal e endividamento. Brasília: Instituto de Pesquisa Econômica Aplicada, out. 2006. Texto para Discussão IPEA No 1223. Brasilia: IPEA. Out. 2006. Disponível em http:// core.kmi.open.ac.uk/download/pdf/6225709 Acesso 15 de Nov. 2010

FIRJAN - Federação das Indústrias do Estado do Rio de
Janeiro. IFDM: Índice FIRJAN de Desenvolvimento Municipal. Ano Base 2007. Ano 3, 2010. Disponível em: $<$ http://www.firjan.org.br>. Acesso em: 15 mar. 2011.

MACEDO, Joel de Jesus; CORBARI, Ely Célia. Os efeitos da lei de responsabilidade fiscal no endividamento municipal: uma análise de dados em painéis. Revista Contabilidade \& Finanças, v. 20, n. 51, set./dez. 2009, p. 44-60.

MACHADO, Joyce de Andrade. A Lei de

Responsabilidade Fiscal e o impacto sobre o endividamento dos Municípios Paranaenses.

Monografia apresentada ao Curso de Ciências Econômicas da Universidade Estadual do Oeste do Paraná, Campus Francisco Beltrão, 2010.

MAROCO, João. Análise estatística: com utilização do SPSS. Lisboa: Silabo, 2003.

MATIAS, Alberto Borges; CAMPELlO, Carlos A. G. B. Administração Financeira Municipal. São Paulo: Atlas, 2000.

MARTINS, Gilberto de Andrade. Manual para elaboração de monografias e dissertações. 3 ed. São Paulo: Atlas, 2002.

MELLO, Gilmar Ribeiro de; MACEDO, Fabrício de Queiroz; TAVARES FILHO, Francisco; SLOMSKI, Valmor. Identificando o endividamento dos estados brasileiros: uma proposta através de análise discriminante. Enfoque Reflexão Contábil, v. 25, n. 1, jan./abr. 2006, p. 05-14.

MELLO, Gilmar Ribeiro de; SLOMSKI, Valmor; CORRAR, Luiz João. Estudo dos Reflexos da Lei de responsabilidade fiscal no endividamento dos Estados Brasileiros. UNB Contábil, v. 8, 2005, p. 41-60.

MENDES, Marcos. Descentralização Fiscal Baseada em Transferências e Captura de Recursos Públicos nos Municípios Brasileiros. Tese de Doutorado apresentada ao Departamento de Economia da Faculdade de Economia, Administração e Contabilidade, da 
A Lei de Responsabilidade Fiscal (LRF) e o impacto sobre o endividamento dos municípios potiguares

Universidade de São Paulo, 2002.

PEDRAS, Guilherme Binato Villela. Dívida Pública: a

experiência brasileira. Tesouro Nacional, Brasília, 2009.

REZENDE, Fernando. Finanças Públicas. São Paulo:

Atlas, 2001.

RIANI, Flávio. Economia do Setor Público: uma abordagem introdutória. 2 ed. São Paulo: Atlas, 1990.

ROSAR, Oscar. Considerações sobre a evolução da Dívida Pública Brasileira nas últimas décadas. Sociedade Brasileira de Economia Política (2007). Disponível em: $<$ www.sep.org.br/artigo/ivcongresso35.pdf $>$. Acesso em: 14 out. 2010.

SILVA, Isabela Fonte Boa Rosa; SOUSA, Maria da Conceição Sampaio de. Determinantes do endividamento dos estados brasileiros: uma análise de dados de painel. Texto $\mathrm{n}^{\mathrm{o}} 259$, Departamento de Economia da Universidade de Brasília, novembro de 2002. Disponível em: <http://vsites.unb.br/face/eco/cpe/ TD/259Nov02IFontes.pdf $>$. Acesso em: 20 nov. 10.

SILVA, William Gledson. Finanças públicas na nova ordem constitucional brasileira: uma análise comportamental dos municípios potiguares, nos anos antecedentes e posteriores da Lei de Responsabilidade Fiscal - LRF. Dissertação de mestrado. Programa de PósGraduação em Economia da Universidade Federal do Rio Grande do Norte, 2009.

TORRES, Ricardo Lobo. Curso de Direito Financeiro e

Tributário. Rio de Janeiro: Renovar, 1993. 